\title{
Talking to the Visuals: Exploring Ideology of Generations through Semiotic Landscape of Whatsapp Statuses
}

\author{
* Mehreen Zafar, Lecturer \\ ** Dr. Muhammad Ahsan, Lecturer (Corresponding Author) \\ *** Muhammad Naeem, Lecturer
}

\begin{abstract}
Whatsapp statuses are an example of computer-mediated communication. The current qualitative and quantitative study aims to explore the ideology of Whatsapp users and highlight the differences among the generations through the semiotic landscape of Whatsapp statuses. The analytical tools of "David Machin and Andrea Mayr" (2012) and theoretical principles of "Kress and Leeuwen" (1996) helped to analyze the multimodal discourse of WhatsApp statuses. A survey was also conducted to know the stance of Whatsapp users. Multimodal Critical Discourse Analysis (MCDA) of 630 Whatsapp statuses of 90 participants in social semiotics represented Post-Millennials, Millennials, and Generation $X$ with clear differences in their ideologies. The differences are louder for gaze, distance, iconography, colors, vector, angle, and frames. The results of the survey show that PostMillennial give much value to Whatsapp statuses as $92 \%$ of them display statuses daily. All three generations have quite separate reasons to use Whatsapp statuses; only informing others is the common reason between Millennials and Generation X. Basically, the users of Whatsapp statuses are the social actors who represent their cognitive meanings socially.

Keywords: Multimodal Critical Discourse Analysis, Whatsapp Status, Multimodality, PostMillennials, Millennials and Generation X

\section{Introduction}

The communication of people has been changed with the growing integration of technology in every day's life. Communication occurs in a particular communicative event that shapes a discourse (Van Dijk, 1993). People reflect their ideology of power and solitude in their social relations and events through complete communication strategies. The mixing of language and other social semiotic resources develop multimodal discourse and society. Many linguists and theorists have made a research on multimodality and social semiotics (Halliday, 1978; Kress \& Leeuwen, 1996; Jewitt, 2009; O'Halloran, 2011). Their approaches highlighted that the social semiotic approach is quite suitable to interpret the multimodal discourse and directs the people to interpret pictures, images or statues, or any other multimodal discourses.

Whatsapp is a social media app where people can communicate personally through their smartphones, phones, and android. The free of cost texting facility of Whatsapp makes it more popular among the users. The use of Whatsapp could be like an addiction where people would like to interact more through the said app; they like to share images, emojis, and videos. Whatsapp has three major display categories calls, status, and chat. Chat is like a messaging service and calls are to connect verbally but status is the section where they display their ideas, believes, opinions, comments, and quotes. The Whatsapp status disappears after 24 hours of being displayed. The Whatsapp status provides the opportunity for the viewer to reply to the displayed status and it also tells the user about who has seen the status. Whatsapp statuses are a good source of communication because displayed status throws the thread of a chat. People can provide positive and negative feedback on statuses; these can be the reasons for developing new relations, switching social relations to intimate relations, contradiction, and cultural acknowledgments. The current research has the aim;

i. To deconstruct the message of multiple modes of Whatsapp statuses.
\end{abstract}

* Department of English, Ghazi University Dera Ghazi Khan, Pakistan. Email: mzafar@gudgk.edu.pk

** Department of English, Ghazi University Dera Ghazi Khan, Pakistan. Email: mahsan@ gudgk.edu.pk

*** Department of English, Ghazi University Dera Ghazi Khan. Email: mnaeem@ gudgk.edu.pk 
ii. To explore the ideology of Whatsapp users through their Whatsapp statuses.

iii. To highlight the differences of generations through Whatsapp statuses.

This article uses the social semiotic approach to go through the meanings of multiple modes of Whatsapp statuses and explore the stance of Whatsapp users. This mixed-method study helped to understand the Pakistani WhatsApp users for their representation within the bound of Whatsapp statuses. The significance of the current study is to uncover the hidden ideology and differences of the Pakistani generations for displaying Whatsapp statuses. The research helps to understand how semiotic tools can communicate the messages in a short but interesting way. The current research can be a bridge between Pakistani generations and foreign generations for using social media apps and can be a way towards future research for comparative study.

\section{Research Questions}

The research questions of the current research paper are;

- What is the role of multiple modes of Whatsapp statuses?

- How do Whatsapp statuses represent the ideology of Whatsapp users?

- How do Whatsapp statuses reflect the differences of the generations?

\section{Theoretical Framework and Review of Related Literature}

Critical Discourse Analysis (CDA) studies the structures of ideology, representing power and authority, which is reflected by speech and writing (Clark, 2007). The linguists working using CDA consider that language is an important tool to create, maintain, and change the social relations in a given context. Language does not mean only words but typography of words is also a language; therefore, language can be of textual and visual features. Van Leeuwen (2005) points out that in any communicative event, different semiotic modes combine to shape multi-modality. O'Halloran, Tan, Smith and Podlasov (2011) included dress, gesture, lighting, movement, gaze, and other semiotic resources all are responsible to convey meaningful messages and they named such discourse as "multimodal discourse". Halliday (1978) presented the theory of social semiotic approach based on Systemic Functional (SF) theory. To understand the multimodal discourse analysis, Jewitt (2009) describes multimodality as an approach to understanding communication and the relationship between communicators. Jewitt (2009) considers four theoretical assumptions to explore multimodality: 1. Language is multimodal and it's all modes covey meanings equally. 2. Each mode in multimodal discourse works to communicate the social function.3. The people, users, and observers shape the meanings through the selection of the modes. 4. The meanings of signs are deduced from multimodal social semiotic resources. Kress (2012) also thinks that the multimodal approach frames all modes as one domain. All semiotic modes work in a harmony, being interconnected to communicate the social message in a particular context. Zhu Yongsheng (2007) in his theory of Multimodal Discourse proposes two kinds of modality; monomodal (to represent one modality in any text) and multimodal (to represent two or more modalities in any text). O'Halloran (2011) supported the theoretical approach which draws the conceptual use of semiotic resources to explore social meanings in communicative events and artifacts.

Hodge and Kress (1995) explained the concept of social semiotics and devised the analytical tools to understand the social meanings of multiple semiotic modes. Social semiotics explains how language and images jointly convey the message and at the same time, these two can create separate multi meanings in multimodal discourse for their different "affordances" (Kress, 2003). Kress and Leeuwen (1996) adopted the theoretical concept of "meta-function" from Halliday's Systemic Functional Grammar and used three meta-functions in "Grammar of Visual" to understand the representational meaning (ideational meta-function), interactive meaning (interpersonal metafunction) and compositional meaning (textual meta-function). Deconstructing the multimodal discourse in any social context, all three meta-functions represent the participants, their interaction, and their relation with others by bringing unity in the discourse. Kress and Leeuwen (1996) have the credit to improve the theoretical principle of the social semiotic approach to multimodal discourse analysis. After that, many other scholars and theorists are using and their theoretical approaches by applying them in multiple ways. Machin and Mayr (2012) followed the theoretical principles suggested by Kress and Leeuwen (1996) and presented the concept of Multimodal Critical Discourse Analysis (MCDA) which is an approach to deconstruct the social semiotics in multimodal discourse. The approach combines the features of multimodal analysis and CDA to identify the ideology of 
users. This is to deconstruct the boundaries of social power and solidarity. Yang Yang (2016) attempted "A social semiotic approach to multimodal discourse of the Badge of Xi'an Jiaotong University" where the researcher highlighted the strong connotations and interpretations attached to the badges by analyzing the representational, interactive, and compositional meanings of the school badge. Nasir (2018) presented "A semiotic analysis of gender discursive patterns in Pakistani television commercials" where he highlighted that TV ads create layers of meanings through semiotic modes at the symbolic level to identify the stereotypical presentation of men and women.

\section{Methods and Materials}

The present study is in a mixed-method paradigm of research. It adopts a descriptive approach to interpret the data using semiotic analytical tools of Machin and Mayr (2012) which are based on the theoretical framework of Kress and van Leeuwen (1996). Polkinghorne (2007) mentioned that qualitative research encloses various approaches. Therefore, Multimodality Critical Discourse Analysis (MCDA) provided insights into the relation of generations and their representation through Whatsapp statuses. A survey was conducted among the selected Whatsapp users to know their stance about Whatsapp statuses. A statistical tool (SPSS 25.0.0.0) was used to measure their participation for Whatsapp statuses.

Table 1: Co-relation among research question, objective and strategy

\begin{tabular}{lll}
\hline Research Question & Research Objective & Research Strategy \\
\hline Question \#1 & Objective \# 1 & $\begin{array}{l}\text { analytical tools of David Machin } \\
\text { and Andrea Mayr (2012) } \\
\text { analytical tools of David Machin } \\
\text { and Andrea Mayr (2012) + } \\
\text { Survey +Kress and van Leeuwen } \\
\text { Objective \# 2 and 4 }\end{array}$ \\
& & $\begin{array}{l}\text { (1996) } \\
\text { analytical tools of David Machin } \\
\text { and Andrea Mayr (2012)+ Kress } \\
\text { and van Leeuwen (1996) }\end{array}$ \\
\hline
\end{tabular}

\section{Sample and Procedure}

The data for the present study were collected during three months; from July 2019 to September 2019. As Whatsapp status disappears after 24 hours; the screenshot of each status was taken for the analysis. The target population was divided into three categories based on the demographic chart given by the Pew Research Center on the web link http://pewrsr.ch/2GRbL5N.

Table 2: Demographic Division of Generations by Pew Research Center

\begin{tabular}{lll}
\hline Label & Birth Period & Characteristics concerning Technology \\
\hline Post-Millennial & $(0-21$ years $)$ & Introducing smartphones, Wi-Fi, and gadgets \\
& & \\
Millennials & $(22-37$ years $)$ & Introducing internet in their lives \\
Generation X & $(38-53$ years $)$ & Introducing computers in their lives \\
\hline
\end{tabular}

The sample consists of 90 participants using Whatsapp statuses; there are 30 Whatsapp users in each category. In total, 630 Whatsapp statuses were considered for qualitative interpretation through MCDA. Seven Whatsapp statuses were captured as screenshots for each participant

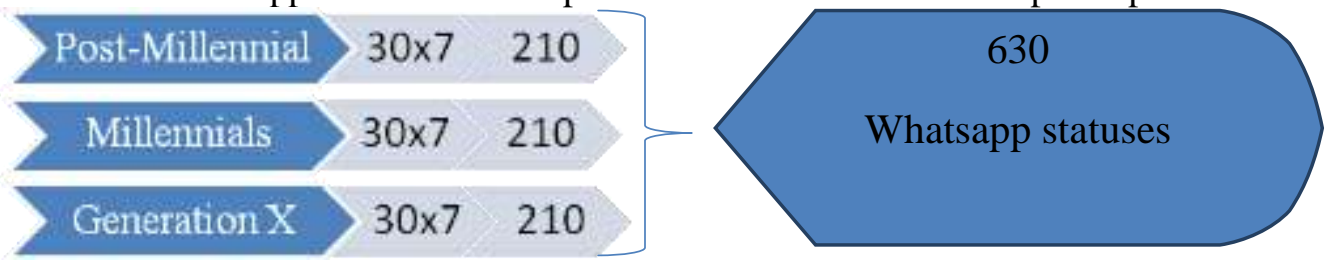

Figure 1: Division of Whatsapp Statuses

The sampling technique used for the current research paper was the non-probability purposive sampling technique. All participants responded in a survey of closed-ended questions about participation for Whatsapp statuses.

\section{Limitation and Delimitation}

The current research is limited to explore the use of Whatsapp statuses by three generations only; the demographic chart represents five generations including Boomers (54-72 years) and Silent (73-90 years). The use of Whatsapp statuses is associated with computer-mediated communication (CMC) and the use of $\mathrm{CMC}$ by Boomers and Silent is exceptional. The reason to identify the differences 
between the selected three generations is the common use of the technology. The display of videos in Whatsapp statues was ignored and only static Whatsapp statuses were selected for data analysis

\section{Data Analysis}

Whatsapp is a source of social media communication which carries not only texts but also shares visuals and recorded or live audio messages and act as computer-mediated communication (CMC). The understanding of $\mathrm{CMC}$, having a focus on online language and language use, was identified as computer-mediated discourse (Herring, 1996).

To do data analysis of the selected Whatsapp statuses, the approach Multimodal Critical Discourse Analysis (MCDA) by David Machin and Andrea Mayr (2012) was used. The data was analyzed to deconstruct the textual and visual modes of Whatsapp statuses and to represent Whatsapp users as social actors (Leeuwen, 1996).

Table 3: Modality of Whatsapp statuses with frequency

\begin{tabular}{ll}
\hline Modality of Whatsapp statuses & Frequency \\
\hline Textual mode with one color only (TM) & 195 \\
Visual model (emoji and pictures) (VM) & 114 \\
Textual and visual mode (TVM) & 321 \\
Total Whatsapp statuses (TM+VM+TVM) & 630 \\
\hline
\end{tabular}

Overall, all participants represent $51 \%$ mixed modality in Whatsapp statuses; they convey textual information along with pictures, emoji, and graphics. A textual mode is $31 \%$ where only textual information (poetry, joke, ironical comment, advice, and wishes) with a colored background is available. 18\% of Whatsapp statuses are of visuals only. The Whatsapp users are reluctant to selfrepresentation. The science of colors and limited self-representation would be discussed in detail under discussion. The individual representation of each generation for using Whatsapp statuses was also measured to identify the generation gap for displaying Whatsapp statuses.

Table 4: Individual representation of modes of Whatsapp statuses for generations

\begin{tabular}{llll}
\hline Generations & TM & VM & TVM \\
\hline Post-Millennial & $34 \%$ & $12 \%$ & $54 \%$ \\
Millennials & $18 \%$ & $24 \%$ & $58 \%$ \\
Generation X & $40 \%$ & $18 \%$ & $42 \%$ \\
\hline Accorl & & &
\end{tabular}

According to Kress (2010), "a mode is a socially shaped and culturally given semiotic resource for making meaning" (79).

Table 5: Summary of MCDA Analysis

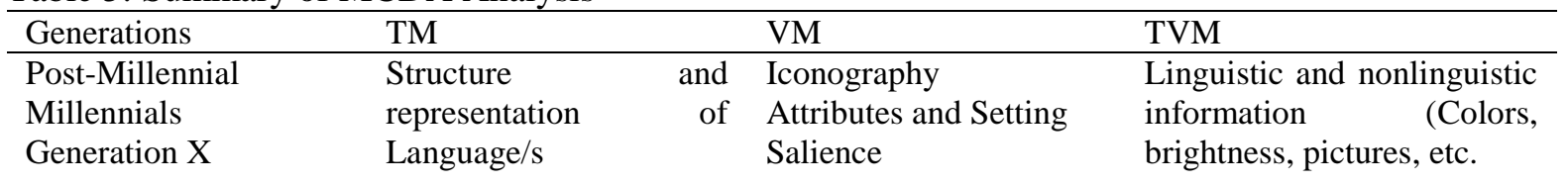

The above table shows the basic division for the analysis and detailed analysis is given below which further leads towards the findings and discussion.

\section{Analyzing Textual Mode}

Post-Millennials use informal language with excessive use of emoji. Their medium is mostly Urdu, Shiraki, and Punjabi (Cultural languages); they use ungrammatical English language, code-mixing, abbreviations, and roman English for Urdu. They use dark colors (purple, green, black, bright pink) for the background and white color for the text to convey textual information. Thematically, they share jokes and poetry.

Millennials use formal and structured language. They use English and Urdu both languages equally in Whatsapp statuses; poetry statuses are in Urdu language and Roman Urdu whereas quotes, comments, and wishes are in the English language. They use very limited emoji. Their textual representation is in white in all Whatsapp statuses with black color in the background. They display wishes, greetings, and poetry.

Generation X share stories, advice, and serious information. They use mostly Urdu language; there is no use of Roman Urdu. Language representation in formal and structured. They present information about the selected text. Their text and background color are in contrast (black-white, blue-white, and red-yellow). There is no use of emoji in their Whatsapp statuses. (Appendix 1) 


\section{Analyzing Visual Mode}

Textual information itself is visual in terms of font size, type, and paper texture but analyzing semiotic visual mode means relatively images and pictures ("Mayr and Machin, 2012"). Overall, out of 630 Whatsapp statuses, 114 (18\%) Whatsapp statuses are of visual mode only; they represent just visual mode without any text. Millennials (22-37 years) use the maximum (24\%) visual mode in Whatsapp statuses whereas the Post-Millennial uses the least (12\%) of it.

Iconography: According to R. Barthes (1977), images denote and connote the message. Through Whatsapp statuses, all three generations denote and connote personal information, ideas, and preferences. Post-Millennial represent limited self-representation, they represent mostly celebrities, actors, and actresses, and events. Connotatively, they highlight the themes of love, activity, and fun.

Millennials share maximum from their personal life; they do add 'caption' with their pictures which is not a direct part of the picture but a comment from them on their picture. They represent their success, achievements, kids, parents, and eatables.

Generation X presents flowers, sceneries, and their pictures in their statuses but their selfrepresentation is very much limited, formal, and professional. Interestingly, out of 38 visual statuses, they represent tea with snacks in 17 Whatsapp statuses and flowers in 13 statuses. (Appendix 2)

Attributes and Setting: Post-Millennial represents informal visual features; 50\% of their pictures are the close-ups of the faces. Millennials and Generation X use formal Whatsapp statuses. The use of bright light in all pictures highlights the openness of the users. Mayr and Machin (2012) suggest optimism through bright light in pictures. Millennials display more pictures of their loved ones or intimate relations in any social gathering and outing places. Generation X presents a bunch of flowers and a formal representation of tea which could be the symbol of invitation in any social gathering.

Salience: Salience is by color, tone, size, foregrounding, overlap, and repetition of elements within an image (Machin, 2007). The variety of all mentioned elements can be observed in the statuses of Millennials. They use blue and black color in most of the statuses; they present their loved ones, kids, and parents as the center of the pictures and highlight the message of care and closeness through the overlapping feature of body parts.

Generation X display bright colors for flowers like red, orange, yellow to highlight the warmth, energy, and passion. There is much repetition in the presentation of their statuses.

Post-Millennials' Whatsapp statuses represent the bright colors, faces in the center, and physical intimacy to highlight friendship and love.

\section{Analyzing Textual and Visual Mode}

Haliday (1985) mentions that presenting lexicogrammatical information with semiotic resources to convey the specific meanings is known as 'multimodality'. All three generations display multimodality $(51 \%)$ in their Whatsapp statuses. They combine textual information with pictures, emoji, and other visual impacts. Machin, (2007) explains that "just as words can be combined in sentences and texts so we can think about visual signs being combined to make visual statements" (03).

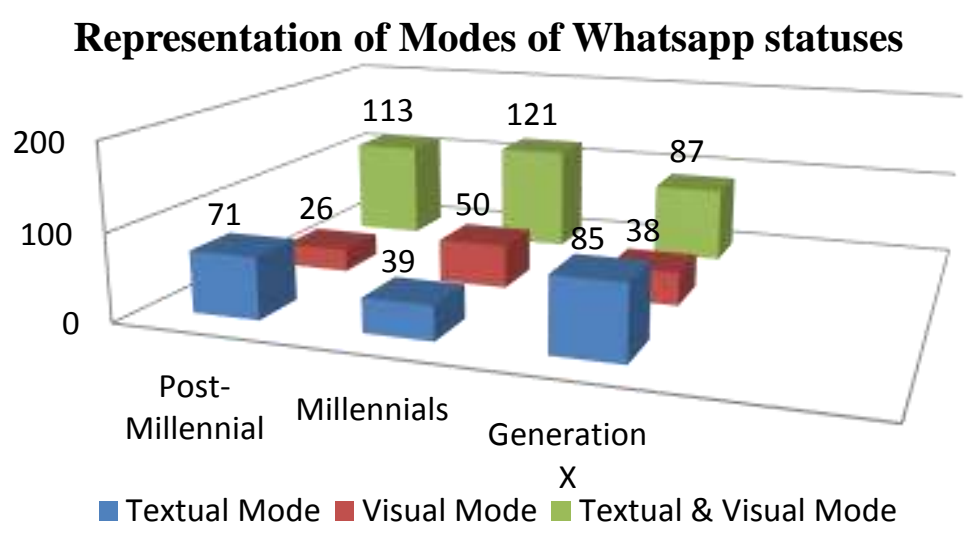

Figure 2: Numerical Representation of Modes of Whatsapp Statuses

Though all three generations use textual and visual combined features in Whatsapp statuses Millennials display multiple modes maximum as compared to others in their Whatsapp statuses. 
They represent wishes, satire, opinion, quotes, and religious thoughts and semiotic features are present to enforce linguistic information. They present information with real images and real names. Whereas the post-Millennials present quotes without a real image to who that quote belongs. They just reflect whatever they want to reflect through their Whatsapp statuses without any authentic source. Post-Millennials represent mostly funny information and for that, they add drawings and images which are not real but a symbolic representation of those words. The use of multimodality is the least by Generation $X$ in their Whatsapp statuses as compared to the other two generations. They present mostly quotes in English but with irrelevant images to present linguistic information.

Post-Millennials use multiple bright colors, drawings, images, emoji in their multimodal statuses to show the symbolic relationship of linguistic and non-linguistic information. To show the symbolic relationship, the youth uses excessive drawings, images, and emoji; it seems that they want to add colors and visual impressions. Millennials use relevant use of linguistic and non-linguistic information but Generation $\mathrm{X}$ is not conscious of attaching text with visuals. They present mostly quotes in English but with irrelevant images to present linguistic information.

There is one genre of multimodal discourse where all have common features to display and that is religious messages. For religious texts, all three generations add religious images either as background or at front. That affirms the use of ideational and interpersonal metafunctions in Whatsapp statuses.

Millennials display more authentic resources and diversity in their statuses as compared to the other generations. The Whatsapp statuses by Generation $\mathrm{X}$ display much lighting effect in multimodal messages. Machin (2007) mentions "backlight is associated with truth, as opposed to a dark backdrop which [may] connote something hidden".

The users of Whatsapp statuses reflect their specific ideology for the viewpoints of their audience by aligning words with images which is their interpersonal expression. Kress and Leeuwen" (2006) highlighted

"One of the crucial issues in communication is the question of the reliability of messages

[such as those evidenced in images]. Is what we see or hear true, factual, real, or is it a lie, a fiction, something outside reality?"

The semiotic analysis of the Whatsapp statuses concerning colors, text, salience, and vectors led towards the ideological differences among the generations which are discussed further below. The frequency of the responses of the participants for the current study was calculated through SPSS and highlighted the frequent status updates, privacy settings, reasons to update statuses, reflection of the personality, and prioritization of status updates.

\section{Findings and Discussion}

The semiotic analysis of multiple modes of Whatsapp statuses suggested that there is a reflection of Whatsapp users' thoughts and personalities in their Whatsapp statuses. Kress and Leeuwen (1996) mention "sign-makers choose forms for the expression of what they have in mind" (13). The communication occurs in a context so that there can be a proper understanding of the message. According to Kress and Leeuwen (1996), the meanings by the users are social. Therefore, Whatsapp users are social actors to develop meanings for the audience. The semiotic choices as representational strategies identify the ideology and placement of people in society [(Fowler, 1991; Van Dijk, 1993) cited in Kress and Leeuwen, 1996]. The representational strategies in the semiotic landscape of Whatsapp statuses present Whatsapp users as social actors who represent their ideology in terms of gaze, pose, distance, angle, vector, and frames.

Gaze and Pose: Post-Millennials females use mostly indirect look in the Whatsapp statuses. They avoid the direct view. Even in some Whatsapp statuses, due to the cultural restrictions, the female users hide their faces by applying emoji on faces or turn the face but the young boys prefer to look in the camera. (Appendix 4)

Therefore, the female Post-Millennials leave implicit meanings for their appearances in statuses. They share personal information but do not allow the viewers to get in their personal life whereas male Post-Millennials reflect explicit images where they allow the viewers to get in their sharing. Millennials display mix approach for gaze. In some statuses, they completely avoid the camera but reflect the full gesture to enlighten the activity in the picture whereas, in some statuses, they display the pictures of direct look for the viewers. They are confident enough to share their 
personal life with others. Kress and Leeuwen (1996) tell about "users use the image to do something to the viewer" (117).

Overall, Millennials allow the viewers to get an imaginary relationship with them through their reflections. Generation $\mathrm{X}$ is very much confined for not showing their personal life. Their representation is very much professional and closed. They highlight their social activity through their direct gaze in the camera as they 'demand' to get close with the viewer in a formal setting only. (Appendix 4)

According to Barthes (1973) poses help to perceive the ideas and believes of the depicted person in the pictures. Both Millennials and Post-Millennials reflect side poses even for the direct look. The viewer can withdraw the meaning of being reserved from their side pose but both generations use mostly 'selfie images' for the self-representation which intend to present the users as open people for the social relationship. Their poses are relaxed not controlled ones. Therefore, the meanings of social closeness are louder enough. Whereas the closed postures of Generation X represent them as formal and professional in their social outlook. Their poses are disciplined which does not allow everyone to enter their close zone.

Distance: Social relations are identified by the distance in real life but in images, the distance is perceived as 'size of frame' (Kress and Leeuwen, 2006).

Table 6: Classification of Distance by Hall (1966) cited by Kress and Leeuwen in "Jaworski and Couplan (1999).

\begin{tabular}{ll}
\hline Different Types of Camera Shot: & Social Meanings of Given Distances \\
\hline 'Close shot'/ 'Closeup' & 'one can hold or grasp the other person' \\
'Medium-close shot' & 'extends from a point that is just outside easy touching \\
& distance by one person to a point where two people can \\
& touch fingers if they both extend their arms' \\
'Medium-long shot' & a little further away, the distance of 'impersonal \\
& business' \\
'the distance to which people move when somebody & says, 'Stand away so I can look at you' \\
'Long shot' & 'the distance between people who are [unknown to each \\
& other] and [who] are to remain strangers' \\
\hline
\end{tabular}

Post-Millennials reflect 'Close shot/Closeup and Medium-close' shot type of camera shot. This shows their friendly attitude and openness to the viewers. Millennials display the 'Close shot/ Close up, Medium-close shot and Medium-long shot' type of camera shot which is also towards the social zone and 'offer' the intimate relationship with the audience. Millennials show more diversity in their distance zones, as they can be in 'intimate and social' circles both. Generation X reflect only 'Long shot' which make them distant from the intimate zone and they remain in a formal and controlled relation with viewers.

Angle: Machin (2007) identified how the view was addressed. Linguistic and visual information develop the angles of being viewed through the Whatsapp statuses.

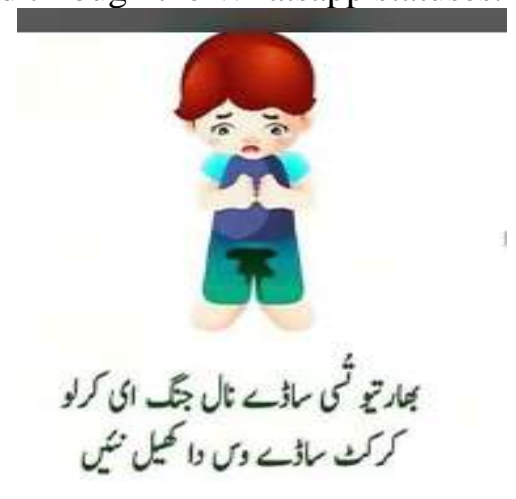

Picture 1: Whatsapp status by Post Millennial

The Whatsapp statuses were seen vertically and horizontally. Kress and Leeuwen cited in Jaworski and Coupland (1999) mention that the horizontal front view involves the viewers directly. The Whatsapp statuses by Post-Millennials capture the attention of the audience fast but the other effects in the semiotic landscape can drop the involvement soon. In the above image, linguistic personal 
address in the sequence of sade (we) and tusi (you) and visual address in terms of 'looking down' of the central character involve the viewer to create a mocking situation of the Pakistani Cricket team. Post-Millennials represent a mostly horizontal but metaphorical association of looking down can dilute the sense of involvement. Jewitt, (2001) comment at eye level, "a relationship of symbolic equality" presides (135). Millennials display more power relations in their Whatsapp statuses. Their statuses representing the frontal side, vertical angle, and extended body posture reflect the power relation between the viewed participant and viewer. Generation $\mathrm{X}$ does not involve the audience through their Whatsapp statuses. They remain detached through most of the visual presentation but in self-representation, they reflect their power position and relation towards the audience.

Vectors: Björkvall (2008) interpreted vectors as "being a powerful visual resource for representing agency (...) in images" (126). These are unidirectional transactional (an arrow connects actor and goal), bidirectional transactional (two-headed participants), and - transactional vectors (an arrow in no particular direction). The reason to identify the direction of the vectors is to identify the given context and culture in which that image can be represented. All three vectors emanate the participant. The high use of vectors is reflected through the statuses of Post-Millennials and Millennials to represent their state of mind and understanding of the culture but Generation $\mathrm{X}$ represents minimum use of vectors as their statuses are lack actors mostly. Post-Millennials idealize love, care, and friendship through the excessive use of unidirectional and bidirectional transactional vectors but they do not use the non-transactional vector. That reflects their controlled relationships; their shared ideas are restricted to the already known people. Mostly, they represent bidirectional transactional relations; they remain in actor and goal relations.
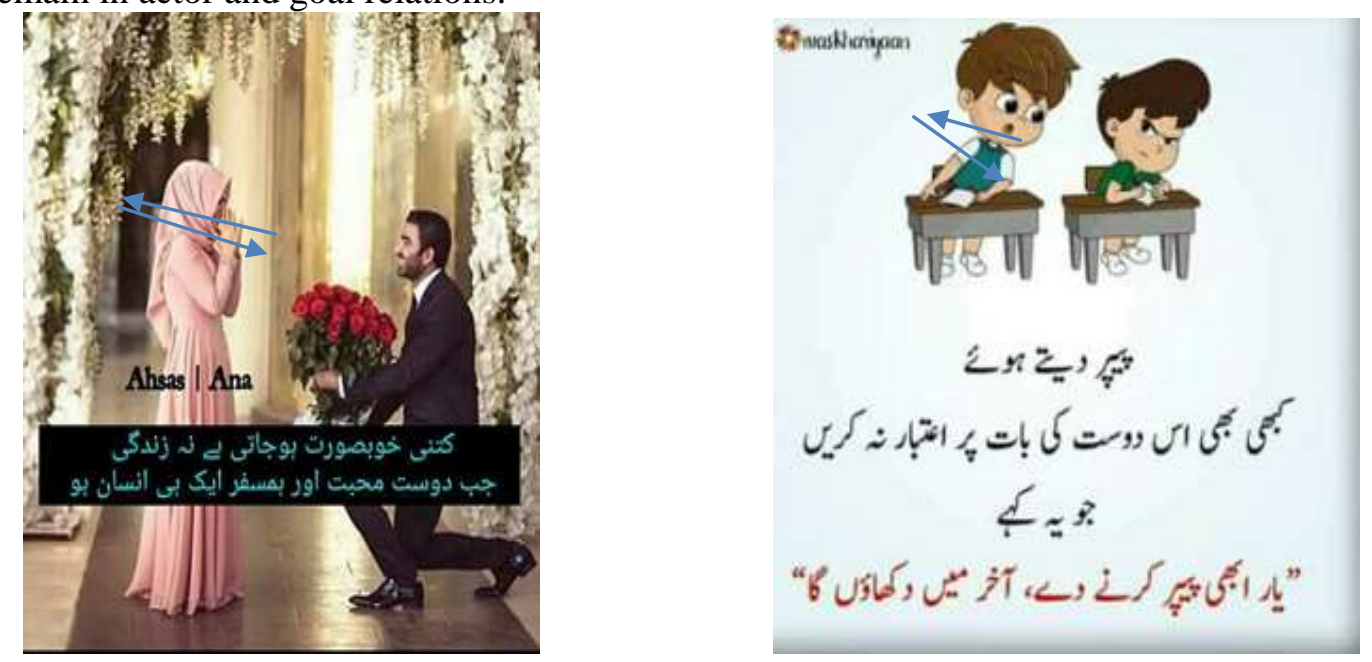

Picture 2: Whatsapp statuses by Post-Millennials

Millennials reflect all three vectors in their Whatsapp statuses. The use of - transactional vectors is mostly observed. They convey their message at a broader level; their message through visuals is not restricted to a particular group of people as Post-Millennials do so.

Frames: Erving Goffman (1974) identified the importance of framing devices and assert that 'the communicative events that occur within a frame'. All three generations use framing devices to clear textual information. The difference is only in their ideologies. Post-Millennials transfer funny information through the pictures, drawings, emoji, and labels but Millennials and Generation X display serious messages; they do not use immature representation in the semiotic landscape to complete the text and bring authenticity and internal unity in the statuses.

The only difference between Millennials and Generation X concerning frames is the length of the message and position of the message. Millennials represent short textual message in the center of the status whereas Generation $\mathrm{X}$ reflects lengthy information either at the top or bottom of the Whatsapp status. (Appendix 5)

Colour: All 630 Whatsapp statuses represent colors. Post-Millennials represent warm and bright colors for monomodal and multimodal Whatsapp statuses. That is to show their energetic and thrilling life activities and they represent the care-free style of commenting just to share fun and laughter. Millennials use mix approach for colors even. They add colors according to the nature of textual information. They use light and dark colors both of which are the reflection of their mature and 
sensible use of Whatsapp statuses. Generation X represents light colors but they present dark colors for the flowers that identify their warm wishes and greetings. For displaying religious messages, almost all users display black color which is connotative in a social, cultural, and religious context.

The results of the survey help to identify the stance of the different generations to display Whatsapp statuses.

Due to the constraint of the study, it is not possible to put all the frequencies for all responses; therefore, only the highest frequency for the relevant response of all generations is mentioned.

Table 7: Frequency differences to show the stance of generations about Whatsapp Status

\begin{tabular}{llll}
\hline Labels & \multicolumn{2}{l}{ Generations with frequency } & \\
& Post-Millennials & Millennials & Generation X \\
\hline Daily Whatsapp status update & $92 \%$ & $86 \%$ & $68 \%$ \\
No Privacy Settings & $87 \%$ & $67 \%$ & $97 \%$ \\
Reason to update status: & & & \\
To fun & $72 \%$ & ------- & -------- \\
To kill spare time & $17 \%$ & $58 \%$ & ------ \\
To share idea/opinion & ------- & $40 \%$ & $52 \%$ \\
To inform others & ------- & ----- & $32 \%$ \\
To be in touch & ----- & $87 \%$ & $34 \%$ \\
Status reflects personality & $88 \%$ & $79 \%$ & $61 \%$ \\
Importance to Whatsapp status & $88 \%$ &
\end{tabular}

The above frequency for different responses of Whatsapp Users represents the stance of the users about Whatsapp statuses. The updating of Whatsapp statuses by Post-Millennials is very much high but they share the information just for fun and sparing extra time. They do not set privacy settings usually and they deny the much reflection of personality through status. Millennials display statuses to reflect meanings that are in their mind. They are share ideas and opinions more without privacy settings for representing their inner personality through statuses. They find it a way of catharsis. Generation X has limited updates concerning Whatsapp statuses as they consider them a source to inform others. Their statuses are not the replica of the personality. The individual textual and visual mode analysis suggests that Whatsapp statuses reflect the hidden meanings that are residing in the mind of the users. The analysis represents the mindsets of the users. The above discussion and the results of the survey ensure the ideological differences among the generations for displaying Whatsapp statuses.

\section{Conclusion}

The semiotic landscape and its analysis clarify the purpose of the multiple modes of Whatsapp statuses and the ideology of individual users and the differences among the generations concerning Whatsapp statuses. The reason for using Whatsapp statuses is also a big source to identify the ideology of the user and further, it is evident through MCDA in the semiotic landscape of Whatsapp statuses. There is a clear difference among the generations for Whatsapp status. Though some features like black color, vector, angle, and frames overlap but their strategy to use and represent the particular message in a specific context stands them separate from each other. Gaze and distance play a major role to identify their ideology. Iconography is also one of the major resources to draw the distinguishing line among generations. Millennials show more diversity in their use of Whatsapp statuses and use authentic references to support textual information. Post-Millennials show nonserious attitude through semiotic attributes of Whatsapp statuses. Generation $\mathrm{X}$ is very much formal and displays a controlled social zone through Whatsapp statuses. To conclude, the current research achieved the research objectives by deconstructing the textual, visual, and mixed modality of Whatsapp statuses. The semiotic analysis of Whatsapp statuses identified Post-Millennials as informal users to seek fun in conveying multimodal messages whereas Millennials and Generation $\mathrm{X}$ have serious concerns to use Whatsapp statuses. The current study recommends Pakistani generations be careful about displaying their content through Whatsapp statuses; though the status can be disappeared after 24 hours the viewers can get screenshots of the statuses and the privacy of the users can be harmed. The study suggests that viewers of Whatsapp statuses can approach the mindset of the users through semiotic analysis and can infringe the users of Whatsapp statuses. Therefore, the users especially Post-Millennials and Millennials should be careful about displaying statuses. 


\section{References}

Barthes, R. (1977). Image-Music-Text, London, Fontana

Bezemer, J. \& Jewitt, C. (2011). Multimodal Analysis: Key Issues, London: Routledge

Björkvall, A. (2008) 'Review of Introduction to Multimodal Analysis' by David Machin. In Visual Communication, 2008/7, 125

Creswell, J. W., \& Clark, V. L. P. (2007). Designing and conducting mixed methods research. Sage Publications, Inc.

Goffman, E. (1974). Frame Analysis: An Essay on the Organization of Experience. . New York, NY et al.: Harper \& Row.

Halliday, M.A.K. (1978). Language as Social Semiotic: The Social Interpretation of Language and Meaning. London: Arnold.

Herring, Susan C. (ed.) (1996).Computer-mediated communication: Linguistic, social, and crosscultural perspectives. Amsterdam: John Benjamins

Hodge, R., and Kress, G. (1988). Social Semiotics, Cambridge, Polity Press

Howard Riley (2014). Interpreting Pictures: Systemic Functional Semiotic Model for visual imagery, IASS Publications, DOI: 10.24308/is-2014-047

Jaworski, A., and Coupland, N. (eds.) (1999). The Discourse Reader. London: Routledge.

Jewitt, C. (2009). The Routledge Handbook of Multimodal Analysis. London: Routledge

Kress, G. \&Van L. (1996). Reading Images: The Grammar of Visual Design. London: Routledge

Kress, G. (2003). Literacy in the New Media Age. London: Routledge.

Kress, G. and T. van Leeuwen (2nd edn) (2006). Reading Images: The Grammar of Visual Design. London: Routledge

Kress, G. (2010). Multimodality - A Social Semiotic Approach to Contemporary Communication. New York: Routledge

Kress, G. (2012). Multimodal Discourse Analysis. In J.P., Gee \& M. Handford (Eds.).

Machin, D. (edn) (2007). Introduction to Multimodal Analysis. London: Arnold

Machin, D., \& Mayr, A. (2012). How to do critical discourse analysis: A multimodal introduction. Los Angeles: SAGE

Muhammad H. N. (2018). A Semiotic Analysis of Gender Discursive Patterns in Pakistani Television Commercials, International Journal of English Linguistics; Vol. 8, No. 4

O'Halloran, K. L. (2011). Multimodal Analysis and Digital Technology.Interdisciplinary Perspectives on Multimodality: Theory and Practice. Campobasso: Palladino.

O'Halloran, K. L., Tan, S., Smith, B. A. \& Podlasov, A. (2011). Multimodal Analysis within an Interactive Software Environment: Critical Discourse Perspectives. Critical Discourse Studies, 2,109-125.

Pew Research Center on web link http://pewrsr.ch/2GRbL5N. (Retrieved on 20.9.2019)

Polkinghorne, D. E. (2007). Validity Issues in Narrative Research. Qualitative Inquiry, 13(4), 471486. https://doi.org/10.1177/1077800406297670

Teun A. van Dijk (1993). Critical Discourse Analysis, https://doi.org/10.1177/0957926594005004001

Van Leeuwen, T. (2005). Introducing Social Semiotics. London: Routledge.

Yang, Y. (2016). A Social Semiotic Approach to Multimodal Discourse of the Badge of Xi'an Jiaotong University, Theory and Practice in Language Studies, Vol. 6, No. 8, pp. 1596- 1601

Zhu, Y. (2007). Theory and Methodology of Multimodal Discourse Analysis. Foreign Languages Research, 5, 82-86. 